\title{
Subcutaneous Rupture of the Long Extensor Tendon of the Thumb: About 12 Cases
}

ISSN: 2576-8875

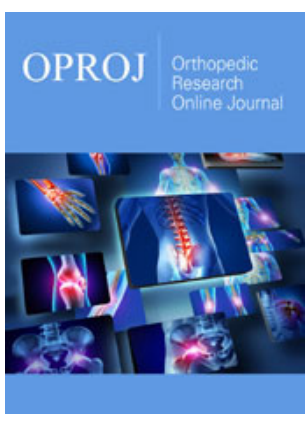

*Corresponding author: Achegri Abderrahim, Department of TraumatoOrthopedy A, IbnoTofail Hospital, University Hospital Center Mohamed VI, Faculty of Medicine and Pharmacy, Marrakesh, Morocco

Submission: 制 June 01, 2020

Published: 海June 15, 2020

Volume 7 - Issue 2

How to cite this article: Achegri Abderrahim, Robleh S, Nassiri $M$ Chafik R, MadharM, Elhaoury H, Najeb Y. Subcutaneous Rupture of the Long Extensor Tendon of the Thumb: About 12 Cases. Ortho Res Online J. 7(2). OPROJ. 000658. 2020.

DOI: 10.31031/OPROJ.2020.07.000658

Copyright@: Achegri Abderrahim, This article is distributed under the terms of the Creative Commons Attribution 4.0 International License, which permits unrestricted use and redistribution provided that the original author and source are credited.

\author{
Achegri Abderrahim*, Robleh S, Nassiri M, Chafik R, MadharM, Elhaoury H and \\ Najeb Y \\ Department of Traumato-Orthopedy A, University Hospital Center Mohamed VI, Morocco
}

\section{Summary}

The subcutaneous long extensor of the thumb muscle (EPL) rupture of the tendon is rare and mainly reported after the distal radius trauma, or following a rheumatic disease. We report a serie of 12 cases of spontaneous rupture of the long extensor tendon of the thumb, treated by a tendon transfer.

Keywords: Tendon; Thumb extensor; Rupture; Hand

\section{Introduction}

The subcutaneous rupture of the long thumb extensor is a rare condition which occurs in a traumatic context or following a rheumatic pathology [1], characterized by a deficit in the active interphalangeal extension (retropulsion) of the thumb, without skin opening. Often, direct repair is not indicated, and management consists either of a tendon graft, or a transfer of the proper extensor of the index finger.

\section{Material and Methodology}

This is a retrospective study spread over a period of 04 years from January 1 st 2016 until December 31st 2019, within the orthopedic trauma service A of the IBN TOFAIL CHU Med VI hospital in Marrakech, a serie of 12 patients, operated for resuscitation of the long proper extensor of the thumb, by a transfer of the proper extensor tendon of the index.

Results

The average age of our patients was 40 years old. With a delay between rupture and reconstruction which varies between 4 weeks and 2 years, the etiology was post-traumatic in 7 cases and rheumatoid arthritis in 5 others. The diagnosis was clinical in all cases (Figure 1).

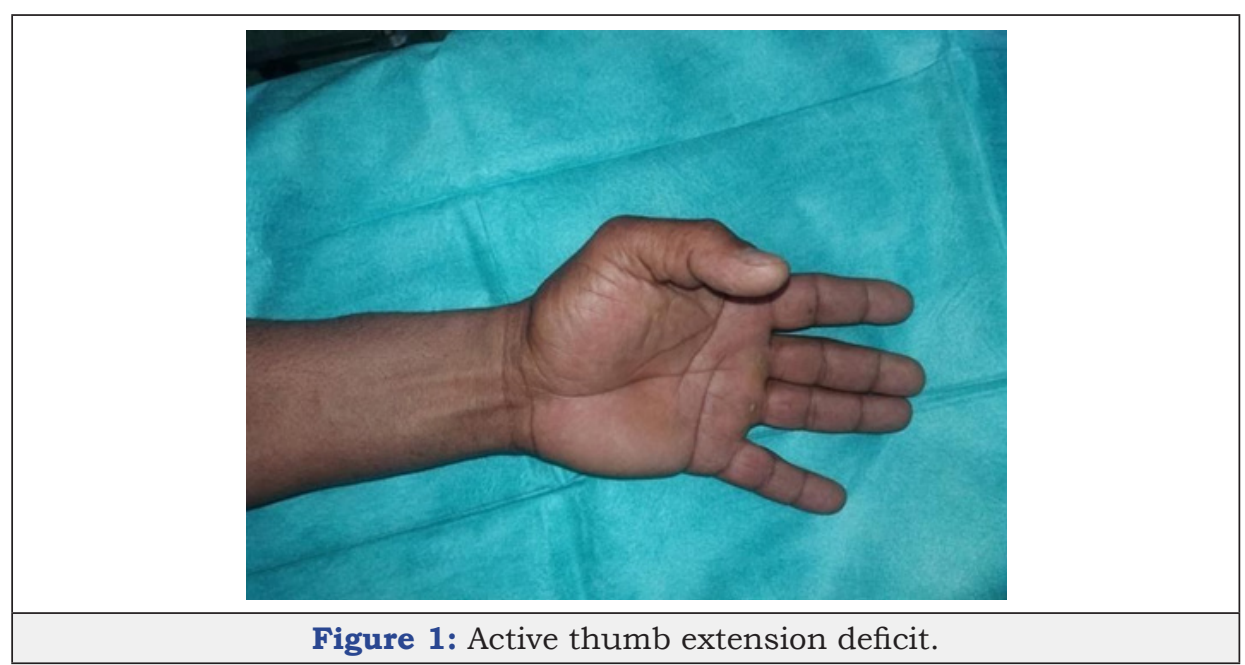

The standard radiography is systematic, the end to-end structure was impossible for all cases, we were calling out for a proper extensor tendon transfer from the 2nd finger in all our patients (Figure 2), The tendon structure was done opposite the dorsal side of the metacarpophalangeal joint in pulvertaft (Figure 3), associated with immobilization with a splint in abduction for 4 weeks. Rehabilitation was prescribed systematically. 

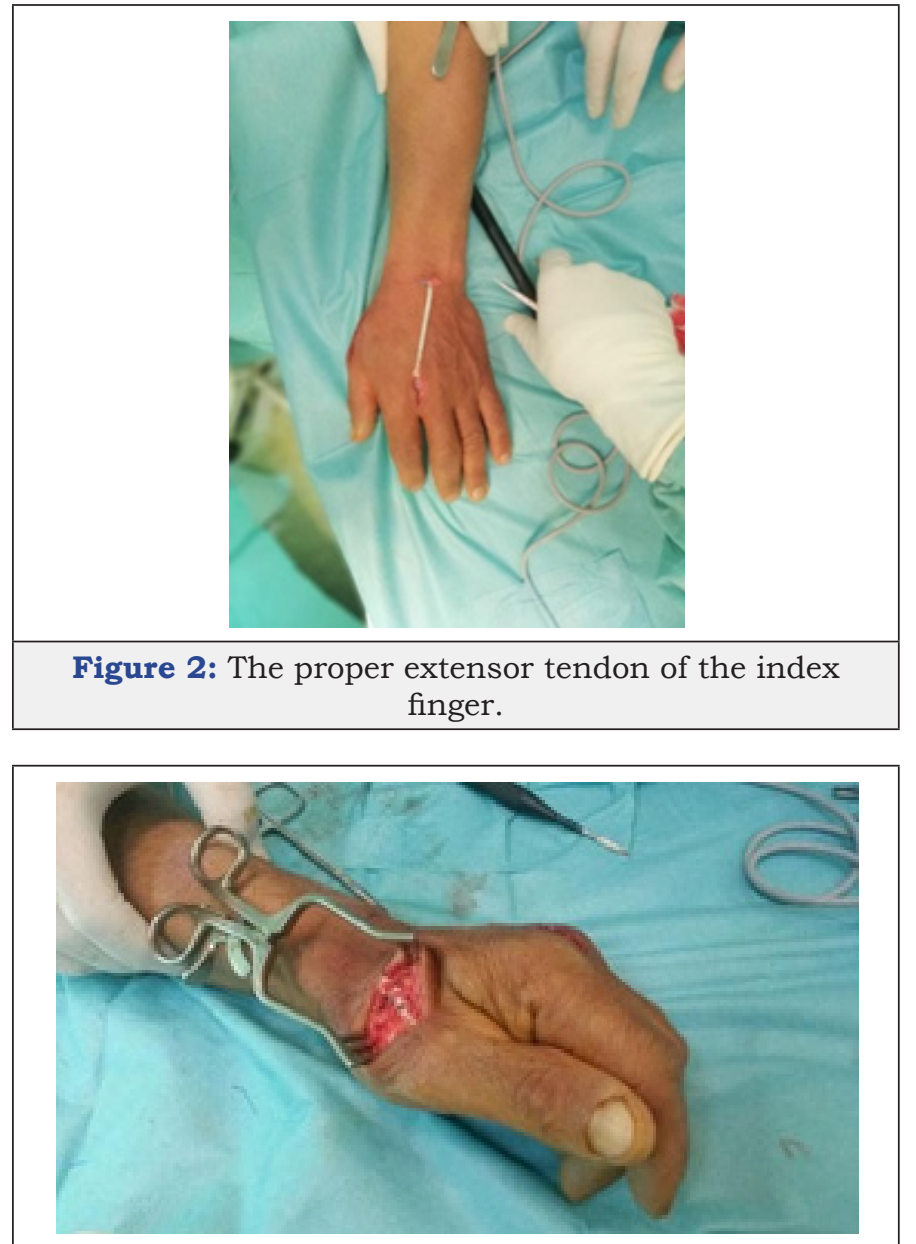

Figure 3: Tendon suture according to pulvertaft.

At the average follow-up of 18 months, no postoperative complication was noted, all of our patients progressed well on the functional level with a very good recovery of the extension of P2 and the retropulsion of the thumb were observed in only 4 patients, without disabling discomfort. In an addition to a decrease in the strength of the index extension among 2 other patients.

\section{Discussion}

The loss of the interphalangeal extension of the thumb indicates the subcutaneous rupture of the long thumb extensor. The most frequent causes described are: traumatic, the lower extremity of the radius and the carpus fracture: little or no displaced, PouteauColles fracture, fracture of the Lister tubercle or direct contusion without fracture [2] on arthritis trapeziometacarpal as described by Apard [1].

Iatrogenic causes following direct damage to the tendon during intrafocal pinning of the lower extremity of the radius fracture, or oral corticosteroid intake [3]. Rheumatic diseases [4] are also found in the literature, from rheumatoid arthritis to Lupus [5] meaning Gout. In off-axis inflammatory wrists with dorsal synovitis. Two theories have been put forward to explain the path physiology of this disorder: vascular theory and mechanical theory. The vascular theory explains that the post-traumatic edema compresses the already very precarious tendon vascularization between the Lister's tubercle and the distal part of the extensor retinaculum [6]. The mechanical theory explains that the rupture is due to the bone attack of a fracture or a vicious cal [2].

The rupture is manifested by a deficit in the retropulsion and extension of the interphalangeal, sometimes difficult to demonstrate when there is a residual extension linked to the action of the intrinsic muscle of the thumb. The diagnosis will then have to be evoked on the context (trauma of the wrist in the previous weeks) and the disappearance of the internal edge of the anatomical snuffbox, normally constituted by the projection of the tendon of the long thumb extensor.

The rupture is easily proven by a simple ultrasound, which finds the tendon interruption, measures the gap between the two ruptured ends and assesses the state of the torn stumps. The repair is done either by grafting of the small palmer or using the small planter, or by a transfer of the proper index extensor, described by Mensch in 1925 remains for us the one of choice. It is indeed comparable to the muscle repaired by its stroke $(55 \mathrm{~mm})$, its strength $(0,5 \mathrm{Kgm})$ and its direction.

It is a simple and reliable technique without significant consequences on the extension of the index. It is performed according to the Pulvertaft process, thus guaranteeing a solid suture.

\section{Conclusion}

Subcutaneous ruptures of the long thumb extensor are relatively rare; several etiologies may be involved, while the treatment must be quickly maintained.

\section{References}

1. Apard T, Marcucci L, Jarriges J (2011) Spontaneous rupture of the long thumb extensor on trapezometacarpal arthritis: a case report and review of the literature. Chir Delamain 30(5): 349-355.

2. Björkman A, Jörgsholm P (2004) Rupture of the extensor pollicis longus tendon: a study of aetiological factors. Scand J Plast Reconstr Surg Hand Surg 38(1): 32-35.

3. Sweetnam R (1969) Corticosteroid arthropathy and tendon rupture. J Bone Joint Surg 51(3): 397-839.

4. Chung US, Kim JH, Seo WS, Lee KH (2010) Tendon transfer or tendon graft for ruptured finger extensor tendons in rheumatoid hands. J Hand Surg Eur 35(4): 279-282.

5. Apard T, Moui Y (2004) Spontaneous rupture of extensor pollicis longus in systemic lupus erythematosus. Chir Main 23(5): 254-256.

6. Engkvist O, Lundborg G (1979) Rupture of the extensor pollicis longus tendon after fracture of the lower end of the radius - a clinical and micro angiographic study. Hand 11: 76-86. 